\title{
Hierarchical CNTs Grown Multifunctional 3D Woven Composite Beams for Aerospace Applications
}

\author{
Firat Turgut ${ }^{1}$ Arda Koycu ${ }^{2}$ and Hulya Cebeci ${ }^{6}$ \\ Faculty of Aeronautics and Astronautics, Istanbul Technical University, Istanbul 34469, Turkey \\ Aerospace Research Center, Istanbul Technical University, Istanbul 34469, Turkey \\ Ghanshyam Neje $\mathrm{e}^{3}$ and Bijoy K. Behera ${ }^{4}$ \\ Department of Textile Technology, Indian Institute of Technology Delhi, Hauz Khas, New Delhi, 110016, India \\ Elif Ozden-Yenigun ${ }^{5}$ \\ School of Design, Textiles, Royal College of Art, SW7 2EU, London, United Kingdom \\ Aerospace Research Center, Istanbul Technical University, Istanbul 34469, Turkey

\begin{abstract}
3D weaving is an innovative approach to eliminate one of the most probable failures as delamination in composites. In this study, two novel approaches of 3D weaving and growing aligned carbon nanotubes (CNTs) directly onto 3D woven fabrics for creating multifunctional properties is performed. First, 3D woven I-beam shaped fabrics were manufactured by a modified weaving loom using glass fibers and followed by growing CNTs onto these I-beams through a chemical vapor deposition (CVD). These 3D woven Ibeams were then impregnated with epoxy resin creating mechanically robust and electrically conductive structural composites without significant weight penalty. The morphological analysis revealed that vertically aligned fuzzy CNTs are successfully grown approximately at $7.5 \mu \mathrm{m}$ long onto 3D woven I-beam glass fabrics. Electrical conductivities of glass fibers were increased in six orders of magnitude after CNTs growth. A reduction in compressive strength (26\%) was observed due to tensile strength reduction of glass fibers after CNTs growth; however, flexural properties were preserved.
\end{abstract}

\section{Nomenclature}

$\sigma_{\max } \quad=$ maximum flexural stress

$M \quad=$ bending moment

$C=$ the distance to the neutral axis in I-beam cross-section

$I_{y y} \quad=\quad$ the secondary moment along the y-axis passing through the centroid of the body

$P \quad=$ force that recorded by the universal testing machine

$L \quad=$ span length

$d \quad=$ height of the I-beam

\section{Introduction}

Transferring load in heterogeneous structures as of composites has been one of the most critical aspects that need to be enhanced. Weak interface and interphase properties have been widely studied problems while many researchers are tackling them through new design and manufacturing approaches. Against delamination failure,

\footnotetext{
${ }^{1} \mathrm{PhD}$ Student, Department of Aeronautical Engineering

${ }^{2}$ Undergraduate Student, Department of Aeronautical Engineering

${ }^{3}$ Post-doctoral Researcher, Department of Textile Technology

${ }^{4}$ Professor, Department of Textile Technology

${ }^{5}$ Senior Tutor, School of Design, Textiles

${ }^{6}$ Associate Professor, Department of Aeronautical Engineering, AIAA member
} 
toughening strategies by modifying reinforcement such as stitching [1], tufting [2], z-pinning [3] were widely studied by others. However, the in-plane properties are sacrificed due to disorienting fibers and resin-rich regions in the structure when these toughening strategies are applied [4]. Besides those strategies, 3D woven fabrics do not require a secondary process for delamination toughening as they already have yarns in the out-of-plane direction, and free of resin-rich regions and disoriented fibers. Hence, out-of-plane mechanical properties in composites such as delamination toughness and impact response [5] can be upgraded by the 3D weaving technique. $3 \mathrm{D}$ woven fabrics also increase the manufacturing efficiency since they are woven into near-net-shaped 3D preforms that are ready for resin infusion. As an alternative route, developing hybrid composites that include nanomaterials like CNTs besides fiber reinforcements is another approach to achieve tougher and multifunctional composites. Several novel approaches incorporating CNTs into fiber-reinforced polymers (FRPs) as surface modification of fibers [6], interlayer toughening [7], matrix toughening [8] have been studied and results showed enhancement in interface properties without weight penalty. On the other hand, CNTs enable to develop conductive composites even when the fibers are insulators by several orders of magnitude due to their high electrical conductivity of CNTs [9] achieved at low percolation thresholds [10].

Although there are several classifications of woven fabrics [5], Nandan Khokar who holds the patents of first $3 \mathrm{D}$ fabrics and methods [11,12] classified them in terms of loom and fabric dimensions [13]. Fabrics can be woven into three dimensions by either $2 \mathrm{D}$ conventional weaving technique or $3 \mathrm{D}$ weaving methods. While two orthogonal yarn sets are used in 2D weaving, at least three orthogonal yarn sets are required. Interest in the 3D woven fabrics that are woven by 2D weaving techniques is growing due to simplicity of weaving mechanism where only slight modifications are necessary to enable 3D woven fabrics by 2D weaving looms [4]. Orthogonal, multilayered, angle-interlocked and hollow fabrics are classes of 3D woven fabrics those woven by 2D looms [5]. Behera and Dash [14] reported the tensile response of 2D unidirectional laminates, 3D woven orthogonal and angle interlocked fabric reinforced composites, and found that 2D laminates are strongest in the warp direction. However, in another comparative study on 2D and 3D woven fabrics [15,16], all of the mechanical properties in in-plane directions such as tensile strength, damage thresholds and failure strains were enhanced for 3D woven orthogonal composite over 2D laminates. Authors stated that overcoming the damage of fibers during weaving for their special weaving method is attributed to the improvements. Besides the prismatic 3D woven fabrics, hollow fabric structures (can be also regarded as "spacer fabrics") also widely studied due to their potential for energy-absorbing mechanisms, lightweight sandwich structures and stiffened panel applications [17]. Badawi [18] and Chen [19] studied the weaving techniques of the hollow fabrics, and additionally mechanical properties of their composites are broadly studied by Neje and Behera [20,21] They applied compressive and flexural tests to the 3D woven hollow composites which have different cross-sections such as triangular, trapezoidal and rectangular. Rectangular channeled composites showed almost 9 times and 2.5 times higher specific load-carrying capacity under compressive loading and flexural loadings, respectively. Triangular channeled composites showed load increase while collapsing under compression when the inclined walls failed and contacted to the ground wall of the composite.

Enhancing advanced composites' fracture toughness, interlaminar and interfacial shear strength has been widely studied through fiber surface modifications using CNTs such as spray coating [22], immersion [23] and electrophoretic deposition of them [24]. Even though CNTs possess a great potential for reinforcing composites, limited improvements have been achieved due to difficulties in processing, dispersing and/or controlling CNT amount and orientation during manufacturing. Besides those methods, direct growth of CNTs by CVD onto fibers provides control of the alignment of CNTs, and therefore higher interlaminar and intralaminar strength can be achieved [25]. Radially aligned CNTs on fibers (also regarded as "fuzzy fibers") by Wicks et al. [26] showed improvements in the delamination toughness of fuzzy alumina fiber-reinforced composites by $76 \%$. In this study, and its subsequent research [25] CNTs grown radially on alumina fibers using Fe ion catalysts by CVD at around $600{ }^{\circ} \mathrm{C}$. The elevated temperatures required for CNTs' synthesis in CVD does not influence mechanical properties of thermally resistant alumina fibers, and conformal coating of aligned CNTs can be easily achieved on them; however, the applications of alumina fibers in engineering applications are limited compared to glass and carbon fibers. While complex functional coatings for preventing damage during CNTs growth was used for carbon fibers [27], He et al. [28] and Malecki and Zupan [29] achieved CNTs growth onto S2-glass fibers with only catalyst coatings similar to on alumina fibers. He et al. reported up to $25 \%, 36 \%$ and $8 \%$ enhancements in flexural strength, tensile strength and IFFS, respectively by hierarchical CNTs that incorporated in S2-glass fiber reinforced composites. Nevertheless, a severe reduction in tensile strength was observed through the CNTs growth onto the other types of glass fibers [30]. Apart from mechanical properties, the electrical conductivity of glass fiber reinforced composites can be increased several orders of magnitude $[31,32]$ due to the hierarchical conductive CNTs network in entire composite structure.

The aim of the study is to fabricate multifunctional structural composites having 3D woven yarn architecture and hierarchical CNTs architectures grown onto insulating fibers. E-glass fibers were used as base material due to their strength, chemical resistance and energy-absorbing capacity [33]. First, 3D rectangular spacer fabrics were woven with a single-end-roving of E-glass fibers using a modified weaving loom. Then, I-beams were extracted 
from the 3D woven rectangular spacer fabric. CNTs were grown onto the 3D woven I-beams and referred as CNT/3DW-IBF with an optimized CVD protocol, and their morphology was characterized by scanning electron microscopy (SEM), and quality and thermal stability were monitored through RAMAN spectroscopy and thermogravimetric analysis (TGA), respectively. Then, the CNTs grown and neat I-beam preforms were impregnated with resin by vacuum infusion process (VIP) to obtain 3D composite beams. The fiber volume fraction of composites was approximately $40 \%$ and, the $4.7 \mathrm{wt} \%$ CNTs achieved in fuzzy glass fibers. There were two different I-beams having $2 \mathrm{~cm}$ and $3 \mathrm{~cm}$ height. $3 \mathrm{~cm}$ high I-beams were for compression tests to investigate the failure of the web clearly, and $2 \mathrm{~cm}$ high I-beams were subjected to 3-point-bending tests with a 1:8 height to span length ratio to increase bending moment. Besides mechanical performance investigation, electrical conductivities of CNTs grown glass fibers were also measured by a four-point probe measurement system.

\section{Experimental Procedure}

E-Glass fibers from Owens Corning company having 600 Tex linear density were used for the weaving of 3D woven I-beam shaped fabrics (They will be referred as 3DW-IBFs, see Table 1 for all specimen labeling). The dimensions of 3DW-IBFs were determined by the warp and weft densities of 3D woven rectangular channeled spacer fabrics that they were extracted from. Two different rectangular spacer fabrics were woven that had $2 \mathrm{~cm}$ and $3 \mathrm{~cm}$ height. The warp density of ground walls and middle walls were $8 \mathrm{~cm}^{-1}$ and $4 \mathrm{~cm}^{-1}$, respectively. The middle walls contained double fabrics which crossed at the middle. Weft density for all walls were $4 \mathrm{~cm}^{-1}$, and the $2 \mathrm{~cm}$ high 3DW-IBFs (2cm-3DW-IBFs) and $3 \mathrm{~cm}$ high 3DW-IBFs (3cm-3DW-IBFs) contain 8 and 12 weft yarns in its middle walls, respectively. The width of the rectangular channeled spacer fabrics was $19.5 \mathrm{~cm}$. The weft cross-section is given in Figure 1. The fabrics were woven by a modified 2D loom (Figure 2) which has the capacity of feeding warp yarns from eight different warp beams. Straight (black) and other (colored) warps were fed into the fabric from different warp beams as they had different lengths in structure. The weaving began with the ground walls and continued simultaneously. Middle walls were woven through the inner part of the fabric, crossed at the middle and woven again together with the ground walls while the straight warps remained non-woven. After weaving of middle walls, the process was paused and straight yarns were rolled back to form the vertical middle walls.
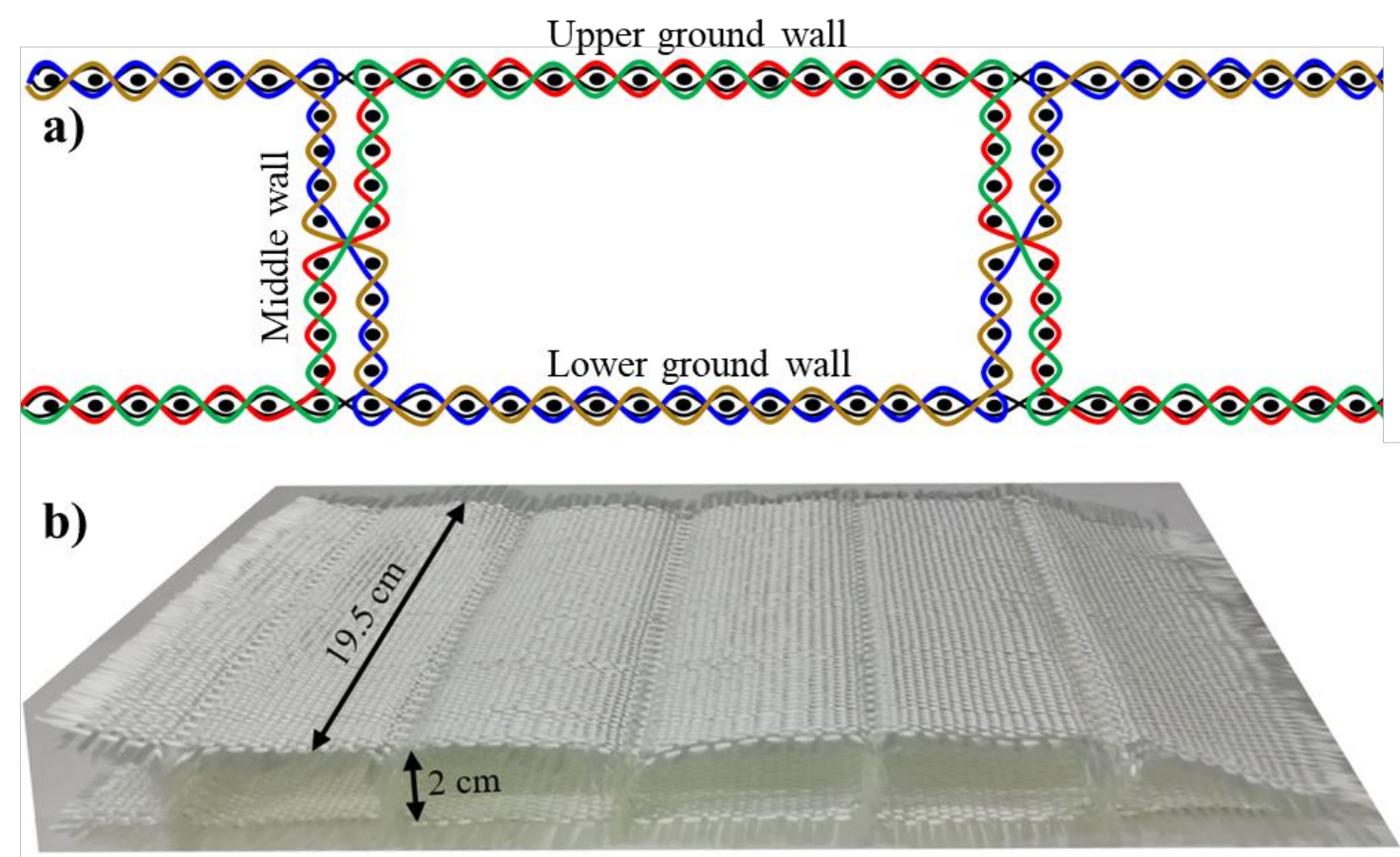

Fig. 1 (a): weft cross-section of rectangular spacer fabric (illustration not to scale), (b): a piece of $2 \mathrm{~cm}$ high rectangular spacer fabric 

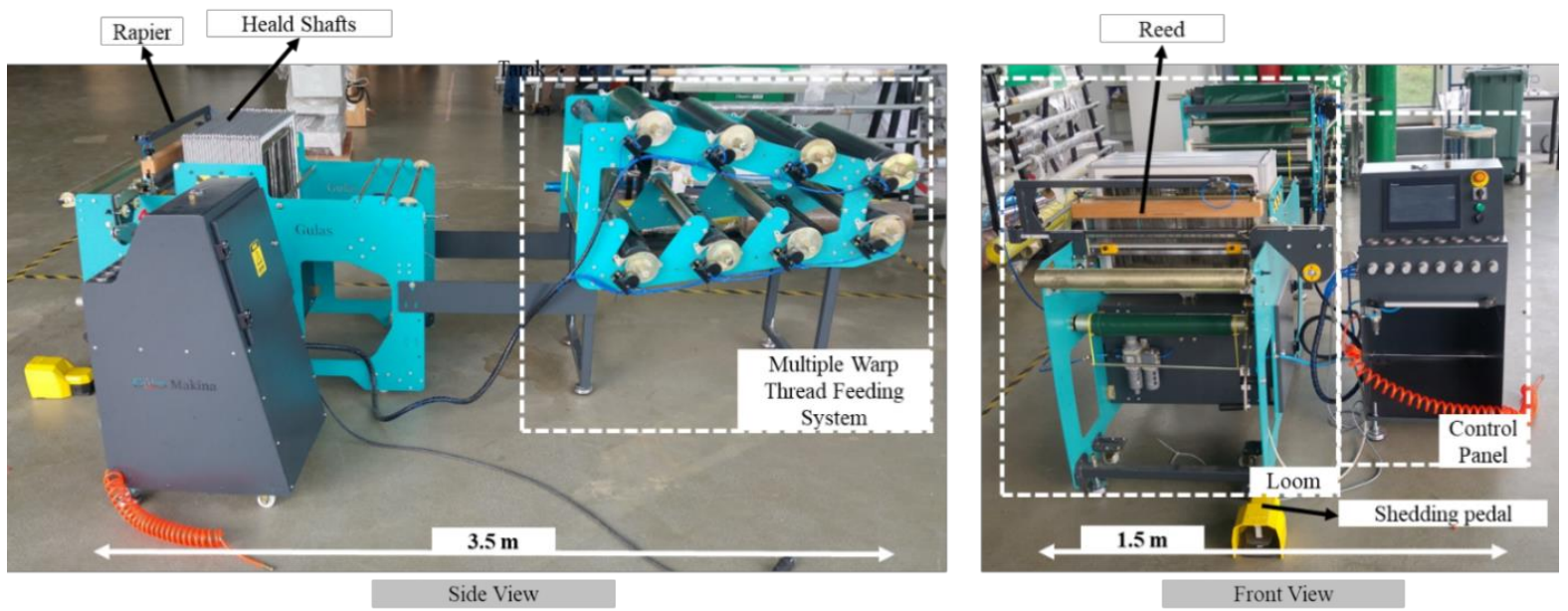

Fig. 2 Modified 2D weaving machine for 3D woven fabric manufacturing

Prior to CNTs growth, $2 \mathrm{~cm}-3 \mathrm{DW}-\mathrm{IBFs}$ and $3 \mathrm{~cm}-3 \mathrm{DW}-\mathrm{IBFs}$ were immersed into $50 \mathrm{mM}$ Iron (III) Nitrate ( $\left.\mathrm{Fe}(\mathrm{NO})_{3} .9 \mathrm{H}_{2} \mathrm{O}\right)$ and Isopropyl alcohol $\left(\mathrm{C}_{3} \mathrm{H}_{8} \mathrm{O}, \% 95\right)$ solution for 5 min. to achieve $\mathrm{Fe}^{+3}$ coating on fibers [34]. These ions act as catalysts in CNTs' synthesis reaction and create nucleation cites for bottom-up CNTs growth onto glass fibers. $19.5 \mathrm{~cm}$ long I-beams were inserted into the tube, nearer to the outlet. An optimized CVD protocol was used to grow CNTs onto glass fibers, and is given as follows:

- cleaning the tube (1) for 2 min. at ambient temperature with $2000 \mathrm{sccm} \mathrm{He}$,

- nucleation (2) for $15 \mathrm{~min}$. with $1600 / 1000 \mathrm{sccm} \mathrm{He} / \mathrm{H}_{2}$ at $600^{\circ} \mathrm{C}$ and

- growth (3) for $12 \mathrm{~min}$. with $400 / 600 / 1000 \mathrm{sccm} \mathrm{C}_{2} \mathrm{H}_{4} / \mathrm{H}_{2} / \mathrm{He}$ at $600^{\circ} \mathrm{C}$.

The hierarchical architectures of CNT/GFs were characterized by SEM at $15 \mathrm{kV}$ under various magnifications using a QUANTA FEG SEM. To investigate the overall CNTs' quality, Raman spectroscopy of CNTs/GFs was conducted using a Renishaw inVia reflex microscopy with a $532 \mathrm{~nm}$ green laser in the range of $100-3000 \mathrm{~cm}^{-1}$. TGA was carried out to determine the thermal stability and the quality of CNTs by measuring their oxidation resistance. The Neat/GF, $\mathrm{Fe}^{+3} / \mathrm{GF}$ and $\mathrm{CNT} / \mathrm{GF}$ were heated to $800^{\circ} \mathrm{C}$ from room temperature $\left(\sim 25^{\circ} \mathrm{C}\right)$ with a heating rate of $10^{\circ} \mathrm{C} / \mathrm{min}$ using TA Instrument SDT Q600 DSC-TGA.

3DW-IBCs were fabricated by VIP. To retain the preform shape after VIP, wooden and Teflon fabric coated two supporting molds were inserted into spaces of the preforms. VIP was conducted on a metal plate, infusion mesh and peel plies were placed on the bottom and top of the preform to ease infusion and demolding. A twocomponent epoxy resin (EPIKURE MGS L160-H160 two-component epoxy resin system) was used at a mixing ratio of 4:1, and curing conditions were 24 hours at room temperature as recommended from the manufacturer. Dimensions of the specimens can be found in Table $1.2 \mathrm{~cm}-3 \mathrm{DW}-\mathrm{IBCs}$ and CNT $/ 2 \mathrm{~cm}-3 \mathrm{DW}$-IBCs were used for flexural tests, and $3 \mathrm{~cm}-3 \mathrm{DW}-\mathrm{IBCs}$ and $\mathrm{CNT} / 3 \mathrm{~cm}-3 \mathrm{DW}-\mathrm{IBCs}$ were for compression tests. The web thickness and flange thickness of $2 \mathrm{~cm}-3 \mathrm{DW}-\mathrm{IBCs}$ and $3 \mathrm{~cm}-3 \mathrm{DW}-\mathrm{IBCs}$ were $1.22 \pm 0.07 \mathrm{~mm}$ and $0.98 \pm 0.02 \mathrm{~mm}$, respectively and this values were increased to $1.38 \pm 0.08$ and $0.99 \pm 0.01$ for CNT $/ 2 \mathrm{~cm}-3 \mathrm{DW}-\mathrm{IBCs}$ and $\mathrm{CNTs} / 3 \mathrm{~cm}-3 \mathrm{DW}-\mathrm{IBCs}$ due to swelling of fabric after CNTs growth [35]. And the fiber volume fraction was determined by weighing composites before and after infusion, and calculated as $40.6 \pm 2.2 \%$.

The electrical conductivities of Neat/GFs and CNT/GFs were measured by the four-point probe measurement system. 28 measurements were taken for each type of specimen which was found to be sufficient as the deviation in the data was subtle.

SHIMADZU AGS-X $50 \mathrm{kN}$ universal testing machine was used for 3-point-bending and compression tests. For 3 -point-bending span length was $16 \mathrm{~cm}$ and the rollers of supports and cross-head have $6 \mathrm{~cm}$ diameter. For compression tests, flat square faces were used. $15 \mathrm{~N}$ pre-loading was applied for 3-point-bending tests, and the pre-load for compression tests was $45 \mathrm{~N}$. The test speed for both mechanical tests was $1 \mathrm{~mm} / \mathrm{min}$. In both tests, the force and stroke (displacement of the cross-head) were recorded. Five specimens of $2 \mathrm{~cm}-3 \mathrm{DW}-\mathrm{IBCs}$ and CNT/2cm-3DW-IBCs were subjected to 3-point-bending tests, and six specimens of $3 \mathrm{~cm}-3 \mathrm{DW}-\mathrm{IBCs}$ and CNT $/ 3 \mathrm{~cm}-3$ DW-IBCs were tested under compression. Stress was assumed to transferred to the web of I-beams and calculated by dividing the force by area of the web. The flexural stresses were calculated as follows:

$$
\sigma_{\max }=\frac{M c}{I_{y y}}=\frac{\left(\frac{P L}{4}\right)\left(\frac{d}{2}\right)}{I_{y y}}=\frac{P L d}{8 I_{y y}}
$$




\section{Results and Discussion}

The morphological analysis by SEM showed that CNT/GFs were partially covered by aligned CNTs. An SEM image showing $7.57 \mu \mathrm{m}$ CNTs is given in Figure 3. To assess the quality of CNTs onto fibers, RAMAN Spectroscopy which is a powerful, non-destructive, and fast characterization technique was utilized. Figure 4a shows the Raman spectra of the grown CNT/GF. The typical peaks of CNTs were detected at c.a $1583 \mathrm{~cm}-1$ and c.a $1346 \mathrm{~cm}-1$ for CNTs, and they correspond to $\mathrm{G}$ and D bands, respectively. The intensity ratio, $\mathrm{I}_{\mathrm{G}} / \mathrm{I}_{\mathrm{D}}$ of CNTs was 0.91 . This ratio indicates that the amount of defective carbons are more than graphitic carbons. The $\mathrm{I}_{\mathrm{G}} / \mathrm{I}_{\mathrm{D}}$ around 1 is a typical value for CNTs that were grown onto fibers at around $600{ }^{\circ} \mathrm{C}$ growth temperature [28].

CNTs' volume fraction was calculated by TGA data of CNT/GFs, and that is a common approach followed in other studies $[24,36]$. In Figure 4b, the TGA data of Neat/GF, $\mathrm{Fe}^{+3} / \mathrm{GF}$ and $\mathrm{CNT} / \mathrm{GF}$ were given. It was showed that there is only $0.7 \%$ weight loss until $500{ }^{\circ} \mathrm{C}$ and this decrease can be presumed to be moisture accumulating and sizing on the glass fiber surface. In $\mathrm{Fe}^{+3} / \mathrm{GF}$, the weight loss until $500{ }^{\circ} \mathrm{C}$ was recorded as $1.3 \%$, and it indicates that there are solvent residues after catalyst coating in addition to moisture and sizing. For the CNT/GFs, when the temperature reached $700{ }^{\circ} \mathrm{C}$, the weight loss stopped around $6 \%$ and therefore, it was shown that the glass fiber surface was coated approximately with 5\% wt. CNTs excluding other compounds that were found in TGA of Neat/GF and $\mathrm{Fe}^{+3} / \mathrm{GF}$. He et al. [28] studied CNT loadings varying between 0.2 and $7 \mathrm{wt} \%$, and found that enhancements in both mechanical and electrical properties remained similar for CNT loadings greater than $3 \mathrm{wt} \%$. Therefore, $5 \mathrm{wt} \%$ CNT loading obtained in this work can be interpreted as appropriate.

Table 1 Description of abbreviations that were used for specimens and dimensions

\begin{tabular}{|c|c|c|}
\hline Abbreviation for the specimen & Description & $\begin{array}{l}\text { Dimensions [height } \times \\
\text { width } \times \text { length } \mathrm{mm}^{3} \text { ] }\end{array}$ \\
\hline $2 \mathrm{~cm}-3 \mathrm{DW}-\mathrm{IBF}$ & $\begin{array}{c}\text { The } 3 \mathrm{D} \text { woven I-beam that extracted from } 2 \\
\mathrm{~cm} \text { high rectangular spacer fabric }\end{array}$ & $20 \times 40 \times 195$ \\
\hline $3 \mathrm{~cm}-3 \mathrm{DW}-\mathrm{IBF}$ & $\begin{array}{c}\text { The 3D woven I-beam that extracted from } 3 \\
\mathrm{~cm} \text { high rectangular spacer fabric }\end{array}$ & $30 \times 30 \times 195$ \\
\hline $\mathrm{CNT} / 2 \mathrm{~cm}-3 \mathrm{DW}-\mathrm{IBF}$ & The $2 \mathrm{~cm}-3 \mathrm{DW}-\mathrm{IBF}$ after CNTs growth & $20 \times 40 \times 195$ \\
\hline $\mathrm{CNT} / 3 \mathrm{~cm}-3 \mathrm{DW}-\mathrm{IBF}$ & The $3 \mathrm{~cm}-3 \mathrm{DW}$-IBF after CNTs growth & $30 \times 30 \times 195$ \\
\hline Neat/GF & As-received glass fibers & $\mathrm{N} / \mathrm{A}$ \\
\hline $\mathrm{Fe}^{+3} / \mathrm{GF}$ & $\begin{array}{c}\text { The } \mathrm{Fe}^{+3} \text { coated glass fibers that extracted } \\
\text { from } \mathrm{CNT} / 2 \mathrm{~cm}-3 \mathrm{DW}-\mathrm{IBF} \text { or } \mathrm{CNT} / 3 \mathrm{~cm}- \\
\text { 3DW-IBF after dip coating }\end{array}$ & $\mathrm{N} / \mathrm{A}$ \\
\hline $\mathrm{CNT} / \mathrm{GF}$ & $\begin{array}{l}\text { The CNTs grown glass fibers that extracted } \\
\text { from CNT/2cm-3DW-IBF or CNT/3cm- } \\
\text { 3DW-IBF }\end{array}$ & $\mathrm{N} / \mathrm{A}$ \\
\hline $2 \mathrm{~cm}-3 \mathrm{DW}-\mathrm{IBC}$ & $\begin{array}{l}\text { The 2cm-3DW-IBF reinforced epoxy matrix } \\
\text { composite }\end{array}$ & $20 \times 40 \times 190$ \\
\hline $\mathrm{CNT} / 2 \mathrm{~cm}-3 \mathrm{DW}-\mathrm{IBC}$ & $\begin{array}{c}\text { The CNT/2cm-3DW-IBF reinforced epoxy } \\
\text { matrix composite }\end{array}$ & $20 \times 40 \times 190$ \\
\hline $3 \mathrm{~cm}-3 \mathrm{DW}-\mathrm{IBC}$ & $\begin{array}{c}\text { The } 3 \mathrm{~cm}-3 \mathrm{DW}-\mathrm{IBF} \text { reinforced epoxy matrix } \\
\text { composite }\end{array}$ & $30 \times 30 \times 30$ \\
\hline $\mathrm{CNT} / 3 \mathrm{~cm}-3 \mathrm{DW}-\mathrm{IBC}$ & $\begin{array}{c}\text { The CNT/3cm-3DW-IBF reinforced epoxy } \\
\text { matrix composite }\end{array}$ & $30 \times 30 \times 30$ \\
\hline
\end{tabular}




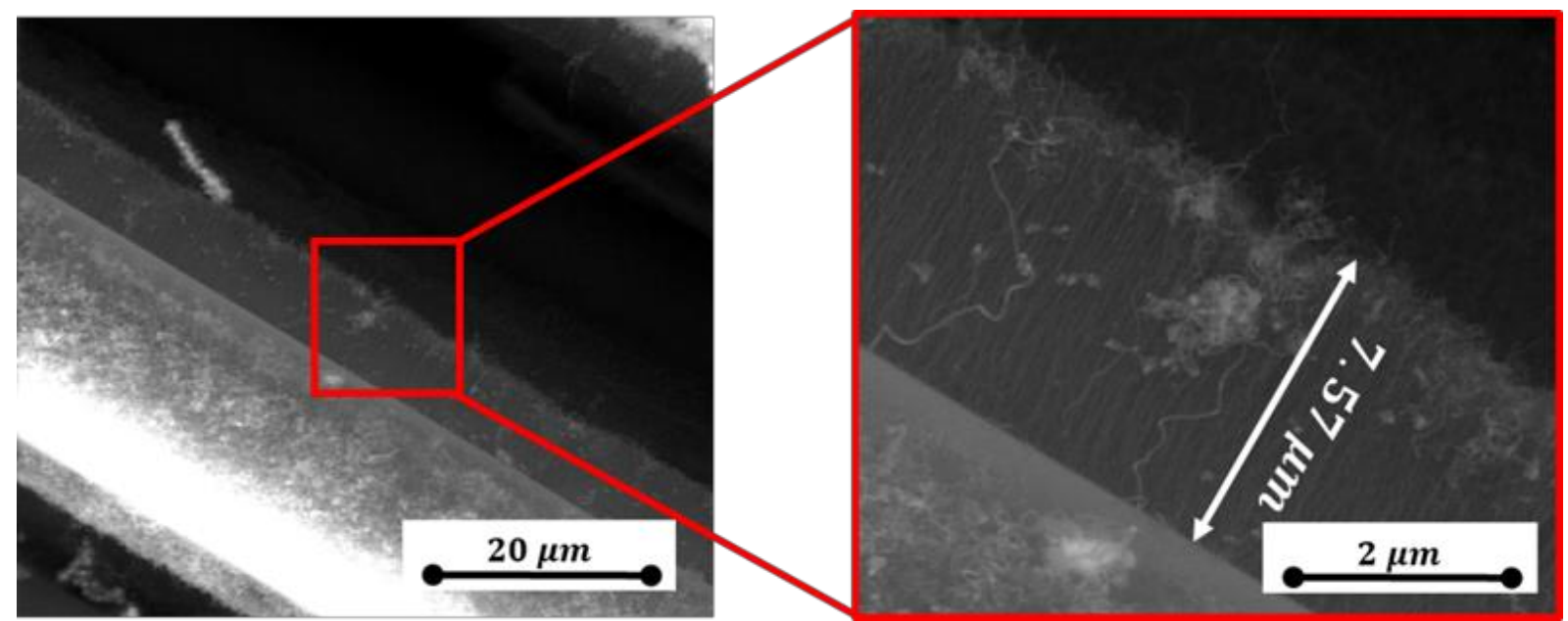

Fig. 3 SEM image of CNTs onto glass fibers
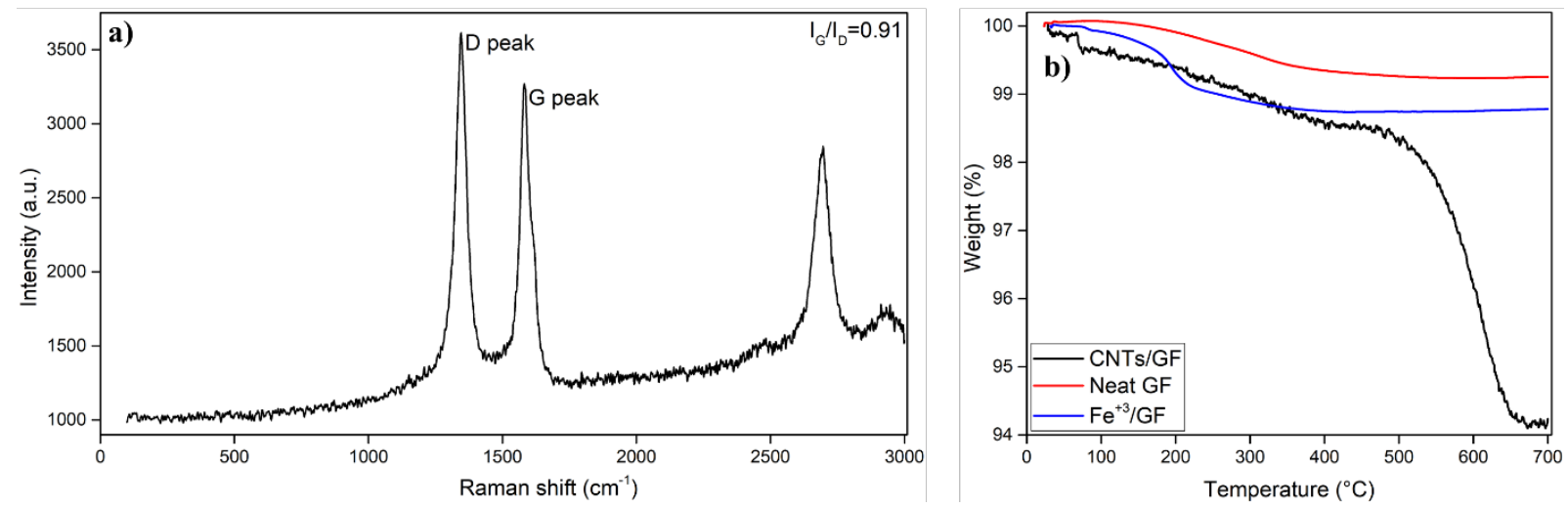

Fig. 4 (a): RAMAN spectroscopy of CNTs onto glass fibers and (b): TGA data of Neat/GF, Fe $\mathrm{C}^{+3} / \mathrm{GF}$ and CNT/GF

The electrical conductivity of Neat/GFs, CNT/GFs were given in Table 2. Electrical conductivity of CNT/GFs were $2.33 \times 10^{-2} \pm 0.44 \times 10^{-2} \mathrm{~S} / \mathrm{cm}$ which was six orders of magnitude higher than Neat/GF. As it was given in earlier study [37], the electrical conductivity of CNTs grown glass fiber fabric was an order of magnitude lower than CNTs grown glass fiber tows since the volume of fabric was much higher than a tow which also might change the quality of catalysis and CNTs growth. Detailed characterization of this electrical conductivity loss will be studied in future studies.

Table 2 Electrical conductivities of glass fibers before and after CNTs growth [37]

\begin{tabular}{cc}
\hline \hline Specimen & Electrical Conductivity (S/cm) \\
\hline Neat/GF & $1.49 \times 10^{-8} \pm 0.18 \times 10^{-8}$ \\
CNT/GF (CNTs grown glass fiber tows) & $2.33 \times 10^{-2} \pm 0.44 \times 10^{-2}$ \\
$\mathrm{CNT} / \mathrm{GF}$ (CNTs grown tows extracted from CNT/3cm-3DW-IBF) & $8.01 \times 10^{-3} \pm 2.74 \times 10^{-3}$ \\
\hline \hline
\end{tabular}

Prior to mechanical tests, it should be mentioned that the tensile strength reduction of CNT/GFs was given in the earlier study [37] which could have effects on compressive and flexural behavior. Table 3 shows the tensile strength of glass fiber tows, after catalyzing, CNTs growth and heating. The heating process includes all of the CVD heating procedures under $2000 \mathrm{sccm}$ Helium. The catalyst coating process in isopropyl alcohol degraded the sizing which was sensitive to alcohol [38], and therefore reduced the tensile strength by $13 \%$. After heat exposure, specimens had been exposed to $600{ }^{\circ} \mathrm{C}$ where the sizing was completely degraded and the flaws on glass fiber surface were grown [39], and then the tensile strength was severely reduced (48\%). The tensile strength reduction was slightly lower for CNT/GFs (44\%) compared to heated glass fiber tows, and it was understood that CNTs growth slightly relieved effect of the high temperatures on the tensile strength reduction. 
Table 3 Tensile strength of glass fibers after catalyst coating, CNTs growth and heat exposure [37]

\begin{tabular}{ccc}
\hline \hline Specimen & Force per Density $\left(\mathbf{N c m}^{3} / \mathbf{g}\right)$ & Reduction $(\%)$ \\
\hline $\mathrm{Neat} / \mathrm{GF}$ & $98.0 \pm 1.6$ & - \\
$\mathrm{Fe}^{+3} / \mathrm{GF}$ & $85.4 \pm 1.1$ & 12.9 \\
$\mathrm{Heated} \mathrm{GF}$ & $51.1 \pm 0.8$ & 47.8 \\
$\mathrm{CNT} / \mathrm{GF}$ & $55.1 \pm 2.7$ & 43.8 \\
\hline \hline
\end{tabular}

In the compression tests, the $3 \mathrm{~cm}-3 \mathrm{DW}-\mathrm{IBC}$ and CNT/3cm-3DW-IBC were loaded laterally. For $3 \mathrm{~cm}-3 \mathrm{DW}$ IBCs the middle longitudinal line of the web where the yarns cross acted as a hinge point to trigger buckling failure. The buckling of webs which was concentrated at the middle line can be clearly seen in Figure 5a. Neje and Behera [20] were observed the same failure at the vertical walls of rectangular spacer composite with the same yarn architecture and loading condition. The maximum stress in the web during the test recorded as $32.9 \pm 1.6$ MPa for $3 \mathrm{~cm}-3 \mathrm{DW}-\mathrm{IBCs}$. CNT/3cm-3DW-IBCs were failed by a crack that separated the middle wall. The crack was initiated at middle longitudinal line of the upper flange, broke the straight warps (black) and grown through the web. An actual image of the failure is given in Figure $5 \mathrm{~b}$, and the failure is illustrated on the weft cross-section of the yarn architecture in Figure 5d. CNT/3cm-3DW-IBCs failed at $24.2 \pm 1.6 \mathrm{MPa}$ stress which was $26 \%$ lower than $3 \mathrm{~cm}-3 \mathrm{DW}-\mathrm{IBCs}$. The rupture of straight warps can be attributed to the reduction in tensile strength of the glass fibers after CNTs growth, and enabled the crack growth through the middle wall which caused an early failure. Two representative stress-strain curve is given in Figure $1 \mathrm{c}$ for both $3 \mathrm{~cm}-3 \mathrm{DW}-\mathrm{IBC}$ and CNT/3cm-3DWIBC.
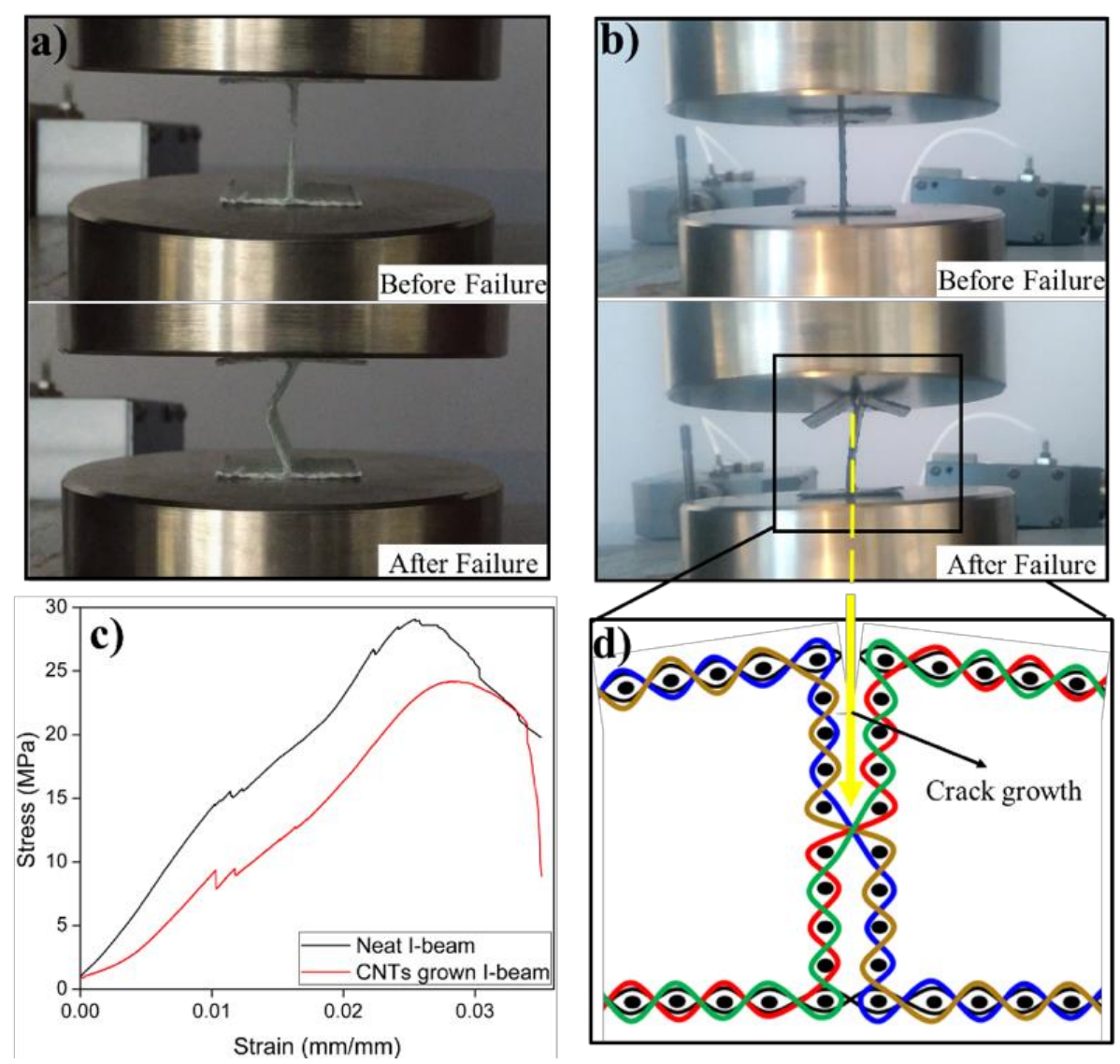

Fig. 5 (a): Compression test of a 3cm-3DW-IBC, (b): Compression test of a CNT/3cm-3DW-IBC, (c): a representative stress-strain curve for a $3 \mathrm{~cm}-3 \mathrm{DW}-\mathrm{IBC}$ and a $\mathrm{CNT} / 3 \mathrm{~cm}-3 \mathrm{DW}-\mathrm{IBC}$ and $(\mathrm{d})$ : illustration of failure with the weft cross-section

For the flexural tests in the earlier study [37], 3D woven I-beam composites with $3 \mathrm{~cm}$ height were used with 9 $\mathrm{cm}$ span length, and buckling failure of the middle wall was the final failure mode of them. In this study, $2 \mathrm{~cm}-$ 3DW-IBCs and CNT/2cm-3DW-IBCs with $16 \mathrm{~cm}$ span length was subjected to 3-point-bending tests. The span 
length to height ratio increased from 3 to 8 , and stresses due to bending moments were expected to determine the failure of beams.

Through the flexural tests of $2 \mathrm{~cm}-3 \mathrm{DW}-\mathrm{IBCs}$, an initial failure was observed at the contact of the upper flange and the roller of the cross-head. This local failure was also monitored in the study by Yau et al. [40], and it did not lead to an overall failure. The local failure was apparently given in Figure 6a. 2cm-3DW-IBCs had reached its ultimate load-carrying capacity just after the distortion. The maximum flexural stress was recorded as $39.2 \pm 4.2$ $\mathrm{MPa}$ for $2 \mathrm{~cm}-3 \mathrm{DW}-\mathrm{IBCs}$. CNT/2cm-3DW-IBCs showed the same failure behavior as it was observed for $2 \mathrm{~cm}$ 3DW-IBCs. The maximum stress observed in the flexural tests for CNT/2cm-3DW-IBCs was $42.0 \pm 2.4 \mathrm{MPa}$ onset of the distortion. Figure $6 \mathrm{~b}$ shows a distorted CNT/ $2 \mathrm{~cm}-3 \mathrm{DW}-\mathrm{IBC}$. Distortion was arisen by the warping of cross-section of the I-beams, and it was understood that the warping stresses dominated the failure. The maximum stresses for the both types of specimens were similar, which shows that the tensile strength reduction of glass fibers after CNTs results did not play a significant role on the failure in flexural tests.
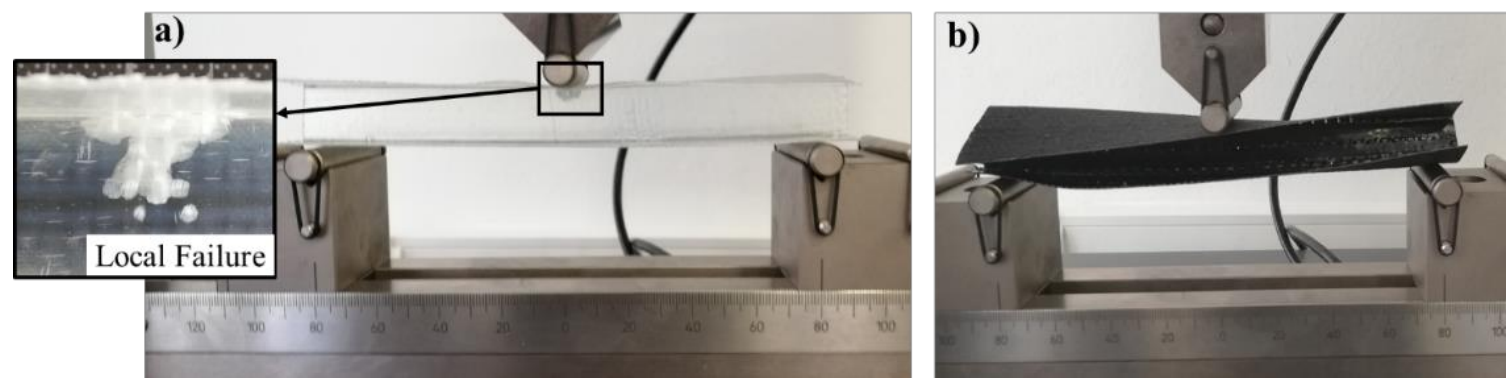

Fig. 6 (a): Flexural test of a 2cm-3DW-IBC and (b): Flexural test of a CNT/2cm-3DW-IBC

\section{Conclusion}

Within the novel approach of CNTs grown 3D woven composites, the multifunctional materials have both 3D woven yarn architecture and CNTs hybridization were manufactured and characterized in this study. Electrical conductivities of CNT/GFs were six orders of magnitude higher than Neat/GFs. Since the tensile strength of the glass fibers was reduced after CNTs growth (44\%) the failure mode of I-beams under compression loading changed and the mechanical performance reduced by $26 \%$. Through flexural tests, I-beams were failed by distortion. It was seen that thin walls of I-beams were showed a significant amount of warping that lead to distortion as the final failure. The maximum flexural stresses for $2 \mathrm{~cm}-3 \mathrm{DW}-\mathrm{IBCs}$ and CNTs $/ 2 \mathrm{~cm}-3 \mathrm{DW}-\mathrm{IBCs}$ were similar. In future studies, manufacturing techniques of 3D woven beams having tunable thicknesses and different cross-sections such as rectangular and trapezoidal will be studied, and mechanical properties of these composites that have thicker walls and increased stability will be investigated.

\section{Acknowledgments}

Authors would like to thank Scientific Research Project Division of Istanbul Technical University, for funding MGA-2017-40738 General Scientific Project which facilitated this study.

\section{References}

[1] K. A. Dransfield, L. K. Jain, and Y. W. Mai, "On the effects of stitching in CFRPs - I. Mode I delamination toughness," Compos. Sci. Technol., vol. 58, no. 6, pp. 815-827, 1998.

[2] I. Gnaba, X. Legrand, P. Wang, and D. Soulat, "Through-the-thickness reinforcement for composite structures: A review," J. Ind. Text., vol. 49, no. 1, pp. 71-96, 2019.

[3] D. D. R. Cartié, "Effect of $z$-fibres ${ }^{\mathrm{TM}}$ on the delamination behaviour of carbon-fibre/epoxy laminates." Cranfield University, 2000.

[4] A. P. Mouritz, M. K. Bannister, P. J. Falzon, and K. H. Leong, "Review of applications for advanced three-dimensional fibre textile composites."

[5] X. Chen, L. W. Taylor, and L. ju Tsai, "An overview on fabrication of three-dimensional woven textile preforms for composites," Text. Res. J., 2011.

[6] S. Storck, H. Malecki, T. Shah, and M. Zupan, "Improvements in interlaminar strength: A carbon nanotube approach," Compos. Part B Eng., vol. 42, no. 6, pp. 1508-1516, 2011.

[7] B. G. Falzon, S. C. Hawkins, C. P. Huynh, R. Radjef, and C. Brown, "An investigation of Mode I and Mode II fracture toughness enhancement using aligned carbon nanotubes forests at the crack interface," Compos. Struct., vol. 106, pp. 65-73, 2013.

[8] A. Godara et al., "Influence of carbon nanotube reinforcement on the processing and the mechanical behaviour of carbon fiber/epoxy composites," Carbon N. Y., vol. 47, no. 12, pp. 2914-2923, 2009.

[9] B. Q. Wei, R. Vajtai, and P. M. Ajayan, "Reliability and current carrying capacity of carbon nanotubes," Appl. Phys. Lett., vol. 79, no. 8, pp. 1172-1174, 2001.

[10] J. K. W. Sandler, J. E. Kirk, I. A. Kinloch, M. S. P. Shaffer, and A. H. Windle, "Ultra-low electrical percolation threshold in carbon-nanotube-epoxy composites," Polymer (Guildf)., vol. 44, no. 19, pp. 5893-5899, 2003. 
[11] N. Khokar, "Network-like woven 3D fabric material." Google Patents, 13-Aug-2002.

[12] N. Khokar, "Woven 3D fabric material." Google Patents, 15-Jan-2002.

[13] N. Khokar, "3D-Weaving: Theory and Practice."

[14] B. K. Behera and B. P. Dash, "Mechanical behavior of 3D woven composites," Mater. Des., 2015.

[15] S. V. Lomov, A. E. Bogdanovich, D. S. Ivanov, D. Mungalov, M. Karahan, and I. Verpoest, "A comparative study of tensile properties of non-crimp 3D orthogonal weave and multi-layer plain weave E-glass composites. Part 1: Materials, methods and principal results," Compos. Part A Appl. Sci. Manuf., vol. 40, no. 8, pp. 1134-1143, 2009.

[16] D. S. Ivanov, S. V. Lomov, A. E. Bogdanovich, M. Karahan, and I. Verpoest, "A comparative study of tensile properties of non-crimp 3D orthogonal weave and multi-layer plain weave E-glass composites. Part 2: Comprehensive experimental results," Compos. Part A Appl. Sci. Manuf., vol. 40, no. 8, pp. 1144-1157, 2009.

[17] X. Chen, "Hollow three-dimensional woven fabrics," in Advances in 3D Textiles, 2015.

[18] S. S. Badawi, "Development of the Weaving Machine and 3D Woven Spacer Fabric Structures for Lightweight Composites Materials," p. 186, 2007.

[19] X. Chen and H. Wang, "Modelling and computer-aided design of 3D hollow woven reinforcement for composites," J. Text. Inst., 2006.

[20] G. Neje and B. K. Behera, "Lateral Compressive Properties of Spacer Fabric Composites with Different Cell Shapes," Appl. Compos. Mater., 2018.

[21] G. Neje and B. K. Behera, "Investigation of mechanical performance of 3D woven spacer sandwich composites with different cell geometries," Compos. Part B Eng., 2019.

[22] H. Zhang, Y. Liu, M. Kuwata, E. Bilotti, and T. Peijs, "Improved fracture toughness and integrated damage sensing capability by spray coated CNTs on carbon fibre prepreg," Compos. Part A Appl. Sci. Manuf., vol. 70, pp. 102-110, 2015.

[23] M. Li, Y. Gu, Y. Liu, Y. Li, and Z. Zhang, "Interfacial improvement of carbon fiber/epoxy composites using a simple process for depositing commercially functionalized carbon nanotubes on the fibers," Carbon N. Y., vol. 52, pp. 109$121,2013$.

[24] Q. An, S. Tamrakar, J. W. Gillespie, A. N. Rider, and E. T. Thostenson, "Tailored glass fiber interphases via electrophoretic deposition of carbon nanotubes: Fiber and interphase characterization," Compos. Sci. Technol., vol. 166, pp. 131-139, Sep. 2018.

[25] S. S. Wicks, W. Wang, M. R. Williams, and B. L. Wardle, "Multi-scale interlaminar fracture mechanisms in woven composite laminates reinforced with aligned carbon nanotubes," Compos. Sci. Technol., vol. 100, pp. 128-135, 2014.

[26] S. S. Wicks, R. G. de Villoria, and B. L. Wardle, "Interlaminar and intralaminar reinforcement of composite laminates with aligned carbon nanotubes,” Compos. Sci. Technol., vol. 70, no. 1, pp. 20-28, 2010.

[27] R. Li, N. Lachman, P. Florin, H. D. Wagner, and B. L. Wardle, "Hierarchical carbon nanotube carbon fiber unidirectional composites with preserved tensile and interfacial properties," Compos. Sci. Technol., vol. 117, pp. 139$145,2015$.

[28] D. He et al., "Design of electrically conductive structural composites by modulating aligned CVD-grown carbon nanotube length on glass fibers," ACS Appl. Mater. Interfaces, vol. 9, no. 3, pp. 2948-2958, 2017.

[29] H. C. Malecki and M. Zupan, "Scalable continuous growth of carbon nanotubes on moving fiber substrates," Compos. Part A Appl. Sci. Manuf., vol. 43, no. 11, pp. 1914-1920, 2012.

[30] H. Kawada, S. Sato, and M. Kameya, Modification of the Interface in Carbon Nanotube-Grafted T-Glass Fiber, vol. 3. 2012.

[31] D. He et al., "Design of Electrically Conductive Structural Composites by Modulating Aligned CVD-Grown Carbon Nanotube Length on Glass Fibers," ACS Appl. Mater. Interfaces, vol. 9, no. 3, pp. 2948-2958, Jan. 2017.

[32] A. Rahaman and K. K. Kar, "Carbon nanomaterials grown on E-glass fibers and their application in composite," Compos. Sci. Technol., vol. 101, pp. 1-10, Sep. 2014.

[33] P. K. Mallick, Fiber-reinforced composites: materials, manufacturing, and design. CRC press, 2007.

[34] H. Qian, A. Bismarck, E. S. Greenhalgh, G. Kalinka, and M. S. P. Shaffer, "Hierarchical composites reinforced with carbon nanotube grafted fibers: The potential assessed at the single fiber level," Chem. Mater., vol. 20, no. 5, pp. $1862-1869,2008$.

[35] S. V. Lomov, S. Wicks, L. Gorbatikh, I. Verpoest, and B. Wardle, "Compressibility of nanofibre-grafted alumina fabric and yarns: Aligned carbon nanotube forests," Compos. Sci. Technol., vol. 90, pp. 57-66, 2014.

[36] R. Zeiler, C. Kuttner, U. Khalid, M. Kothmann, D. Dijkstra, and V. Altstädt, "The role of multiwalled carbon nanotubes in epoxy nanocomposites and resin transfer molded glass fiber hybrid composites: Dispersion, local distribution, thermal, and fracture/mechanical properties," Polym. Compos., Jul. 2015.

[37] F. Turgut, G. Neje, B. Behera, E. Ozden-yenigun, and H. Cebeci, "Hierarchical Carbon Nanotubes Grown on 3D Woven Glass Fiber Preforms for Multifunctional Structural," in 18th European Conference on Composite Materials, 2018, no. June, pp. 24-28.

[38] X. Liu, J. L. Thomason, and F. R. Jones, "XPS and AFM study of interaction of organosilane and sizing with E-glass fibre surface," J. Adhes., vol. 84, no. 4, pp. 322-338, 2008.

[39] J. L. Thomason, U. Nagel, L. Yang, and D. Bryce, "A study of the thermal degradation of glass fibre sizings at composite processing temperatures," Compos. Part A Appl. Sci. Manuf., vol. 121, pp. 56-63, 2019.

[40] S.-S. Yau, T.-W. Chou, and F. K. Ko, "Flexural and axial compressive failures of three-dimensionally braided composite 1-beams," Composites, vol. 17, no. 3, pp. 227-232, 1986. 